\title{
Translocation of chlorpyrifos residue from soil to Korean cabbage
}

\author{
Kyu-Won Hwang ${ }^{1} \cdot$ Joon-Kwan Moon ${ }^{1}$ (i)
}

Received: 1 November 2017/Accepted: 22 December 2017/Published online: 3 February 2018

(C) The Korean Society for Applied Biological Chemistry 2018

\begin{abstract}
The loss of residual chlorpyrifos in soil and the amount translocated to Korean cabbage were investigated in this study. Field trials with Korean cabbage were carried out in two greenhouses located in Yongin (Field 1) and Gwangju (Field 2). Soil and Korean cabbage samples were collected on different days following the treatment of soil with chlorpyrifos at two different rates. The initial amounts of residue in soil were 1.15 and $3.58 \mathrm{mg} / \mathrm{kg}$, and these decreased to 0.22 and $0.49 \mathrm{mg} / \mathrm{kg}$ at 36 days after treatment (DAT) in Field 1. These values were 20.9 and $59.3 \mathrm{mg} / \mathrm{kg}$, decreasing to 3.03 and $5.24 \mathrm{mg} / \mathrm{kg}$ at 43 DAT in Field 2, respectively. In Field 1, the half-life of chlorpyrifos was approximately 15.0 and 10.2 days in soil treated with 0.12 and $0.24 \mathrm{~g}$ a.i. $/ \mathrm{m}^{2}$, respectively. In Field 2 , the half-life of chlorpyrifos was approximately 27.7 and 9.6 days following application of 0.36 and $0.72 \mathrm{~g}$ a.i. $/ \mathrm{m}^{2}$, respectively. When compared with the initial concentration in soil, the absorption ratio of chlorpyrifos residue to Korean cabbage was $0.93-6.01$ and $0.57-2.61 \%$, respectively. Therefore, safe management guidelines for chlorpyrifos in soil used to cultivate Korean cabbage may be suggested as $3.3 \mathrm{mg} / \mathrm{kg}$ regarding the maximum residue limit of chlorpyrifos on Korean cabbage $(0.2 \mathrm{mg} / \mathrm{kg})$.
\end{abstract}

Keywords Chlorpyrifos - Dissipation - Pesticide residue · Soil $\cdot$ Translocation

Joon-Kwan Moon

jkmoon@hknu.ac.kr

1 Department of Plant Life and Environmental Sciences, Hankyong National University, Anseong, Gyeonggi 17579, Republic of Korea

\section{Introduction}

Pesticides are chemicals used to control pests such as fungi, insect, and weeds in order to increase crop productivity. Chlorpyrifos, [O,O-diethyl $O$-(3,5,6-trichloro-2-pyridinyl)phosphorothioate], is a broad-spectrum chlorinated organophosphorus insecticide, acaricide, and nematicide used to control agricultural and household pests $[1,2]$.

Chlorpyrifos inhibits acetylcholinesterase and has potential toxicity against nontarget animals, such as humans [3]. Several studies assessing the safety of chlorpyrifos in mammals have revealed a possible association with birth defects, nervous system disorders, leukemia, and immune system imbalance [4, 5]. Therefore, the United States Environmental Protection Agency (USEPA) prohibited the residential use of chlorpyrifos for the control of termites, and it use for the control of agricultural insects due to its harmful effects on human health [6]. However, this chemical is still used in Korea as a single or mixed product with bifenthrin, cypermethrin, $\alpha$-cypermethrin, or imidacloprid to control mites, aphids, oriental tobacco budworms, apple leaf miners, and rice borers in rice, apple, tobacco, grape, pear, peach, spinach, cucumber, cabbage, and mandarin [7].

Pesticides sprayed on crops, injected into soil, or used to treat seeds can remain in the crop; these residual pesticides have led to concern among consumers. In particular, foliarsprayed pesticide can stick on the leaf of a target plant or drop into the surrounding soil where the crop is growing [8]. Pesticide levels in cultivation soils, such as upland soil, paddy soil, and orchard soil, are monitored by the Korean government. The most frequently detected compounds in upland soil are endosulfan, procymidone, chlorpyrifos, cypermethrin, chlorfenapyr, and alachlor. In orchard soil, 
endosulfan, chlorfenapyr, EPN, chlorpyrifos, alachlor, procymidone, and hexaconazole have been frequently detected [9]. Results from a 4-year analysis of pesticide residues in GAP-certified agricultural products showed that carbendazim, procymidone, endosulfan, chlorpyrifos, cypermethrin, and EPN were detected at rates exceeding $5 \%$. Compounds that were not registered on the detected crops were endosulfan, procymidone, and chlorpyrifos [10]. These results may demonstrate the use of unregistered pesticides on crops or their translocation from pesticidecontaminated soil, since these are systemic chemicals [11].

Numerous studies have investigated the levels of pesticide residues in crops/plants accumulated from contaminated soils [12-17], especially the persistent organochlorine insecticides. Despite the observed effects of soil type on plant uptake, there are no clear ways to estimate the absorbed levels of contaminants in plants grown in different soils. A study investigating $O$-methylcarbamoyloximes uptake, and their substituted ureas with various lipophilicity, from water solution by barley roots was conducted by Brigg et al. [18]. Those authors concluded that the root concentration factors (RCFs, $C_{\text {root }} /$ $C_{\text {water }}$ ) and translocation are not proportional to the octanol-water partition coefficients $\left(K_{\mathrm{ow}} \mathrm{s}\right)$ of the compounds. Similar results showing empirical correlations for pollutants with plants and leaves have also been reported [19-22].

The pollution of soil with pesticides and other substances leads to the subsequent contamination of crops/plants grown in those soils; many soil-incorporated pesticides are known to absorb and translocate to crops/plants [16, 17, 23, 24]. The amount of chlorpyrifos absorbed in cucumber root was found to range from 1.0 to $1.3 \%$ of the initial soil concentration and was not translocated to fruits [11]. Studies with boscalid, chlorfenapyr, fluquinconazole, and tetraconazole found that the concentrations of these chemicals in Korean cabbage or onion were less than $2.5 \%$ compared with the initial soil concentration $[25,26]$.

Pesticide levels in plants depend on various factors that affect the absorption of pesticides, such as the levels of the compound in soil, the physicochemical properties of the pesticide, the types of plants, and the soil type that sustains the plant [27-29].

No study has investigated the absorption or translocation of chlorpyrifos in Korean cabbage from contaminated soil. In this study, we report a decline in chlorpyrifos residue in soils following treatment at different concentrations, and the levels of translocation to Korean cabbage grown in the treated soil in order to ensure the safety of Korean cabbage products.

\section{Materials and methods}

\section{Chemicals and reagents}

Chlorpyrifos analytical standard (99.7\%) was purchased from Fluka ${ }^{\mathrm{TM}}$ (Switzerland). The formulation of $2 \%$ chlorpyrifos GR (Granule, Inbio Co., Ltd, Gunpo, Korea) was obtained from the local market. Acetone, dichloromethane, and n-hexane were HPLC grade (Burdick and Jackson ${ }^{\circledR}$, Ulsan, Korea). Sodium chloride (EP grade) and sodium sulfate anhydrous (EP grade) were from Samchun Pure Chemical Co. Ltd. (Pyeongtaek, Korea). Florisil SPE (solidphase extraction, $1 \mathrm{~g}$ ) cartridge was purchased from Phenomenex (Torrance, CA, USA), and filter papers (Whatman No. 2) were from Whatman International Ltd. (Maidstone, England). A mechanical mixer (NFM-8860, NUC, Seoul, Korea) was used for sample extraction, and a rotary vacuum evaporator from Heidolph (Schwabach, Germany) or a nitrogen evaporator (Hurricane-Lite, Chong min Tech, Seoul, Korea) was used to remove organic solvents.

\section{Field experiment}

The field experiments were conducted in greenhouses located in Yongin city (Field 1) and Gwangju city (Field 2) in Gyeonggi Province, Korea. Triplicate $5 \mathrm{~m}^{2}$ plots of soil in Field 1 were treated with chlorpyrifos for a total area of $15 \mathrm{~m}^{2}$ per treatment. The granule formulation of chlorpyrifos was scattered over soil at a rate of 0.12 or $0.24 \mathrm{~g}$ a.i. $/ \mathrm{m}^{2}$. Field 2 was treated with 0.36 or $0.72 \mathrm{~g}$ a.i. $/ \mathrm{m}^{2}$ to $10 \mathrm{~m}^{2}$ in each test plot. An untreated plot was prepared next to the test plots with a buffering zone of $1 \mathrm{~m}$. Korean cabbage seeds were sowed at a density of $20 \times 20 \mathrm{~cm}$ in the untreated plot or test plots following treatment with pesticide. The temperature and relative humidity in the greenhouse were continuously measured during the cultivation period using an electric data logger (Lascar, Erie, PA, USA). To study the dissipation pattern, soil was collected at $0,7,14,22,28$, and 36 (Field 1) or 0, 7, 14, 25, 35, 39, and 43 (Field 2) days after treatment (DAT). The collected soil samples were air-dried in the shade shadow and sieved using a 10-mesh sieve. After sieving, samples were kept in a refrigerator under $-20{ }^{\circ} \mathrm{C}$ until analysis. The crop samples were collected randomly from the untreated plot and each treated plot at 22, 25, 28, 32, and 36 (Field 1) or 35, 37, 39, 41, and 43 (Field 2) days after sowing. Immediately after picking, the samples were washed with tap water to remove surface contaminants, placed into polyethylene bags, and transported with ice to the laboratory where the roots were removed, and aerial 
samples were homogenized. Each sample was then placed in polyethylene bottles and frozen at $-20{ }^{\circ} \mathrm{C}$ until analysis.

\section{Instrument analysis and calibration curve}

Chlorpyrifos standard $(99.7 \%, 10.03 \mathrm{mg}$ ) was dissolved in $100 \mathrm{~mL}$ acetone to obtain $100 \mathrm{mg} / \mathrm{L}$ stock solution. From this stock solution, a working standard solution $(20 \mathrm{mg} / \mathrm{L})$ was prepared by diluting with acetone; this was then serially diluting to obtain standard solutions of $0.1,0.5,1.0$, 5.0 , and $10.0 \mathrm{mg} / \mathrm{L}$. An aliquot of $1.0 \mu \mathrm{L}$ was analyzed using a gas chromatograph (GC)-electron capture detector (ECD), and a standard calibration curve was prepared based on the peak area. The instrumental conditions are shown in Table 1 .

\section{Recovery of chlorpyrifos and sample analysis}

Samples (soil $20 \mathrm{~g}$, Korean cabbage $10 \mathrm{~g}$ ) were fortified with a standard solution of chlorpyrifos at 0.2 and $1.0 \mathrm{mg} /$ $\mathrm{kg}$. Then, the sample was extracted with $100 \mathrm{~mL}$ of acetone by shaking at $200 \mathrm{rpm}$ with a mechanical mixer for $1 \mathrm{~h}$ followed by filtering through a Whatman filter paper No. 2 under vacuum conditions. The container and the filtrate were washed again with $30 \mathrm{~mL}$ acetone, and the extracts were transferred to a $500-\mathrm{mL}$ separatory funnel. Then, $10 \mathrm{~mL}$ saturated $\mathrm{NaCl}$ solution, $90 \mathrm{~mL}$ water, and $70 \mathrm{~mL}$ dichloromethane (DCM) were added in the separatory funnel, and the funnel was shaken. After shaking, the lower DCM layer was drained into a 500-mL flask through anhydrous sodium sulfate. This partitioning was repeated with $70 \mathrm{~mL}$ DCM. Then, extracts were collected, pooled, and concentrated to dryness using a rotatory vacuum evaporator at $40{ }^{\circ} \mathrm{C}$. Then, the residue was re-dissolved in a $2 \mathrm{~mL}$ mixture of acetone and hexane $(20 / 80, \mathrm{v} / \mathrm{v})$. The concentrated extract was loaded into a foresail SPE cartridge, which was prewashed with $5 \mathrm{~mL}$ of $20 \%$ acetone in hexane. Then, chlorpyrifos was eluted with $8 \mathrm{~mL}$ of $20 \%$ acetone in hexane. The eluted fraction was concentrated using a nitrogen evaporator, and the residue was re- dissolved in $4 \mathrm{~mL}$ acetone (in the case of Korean cabbage, $2 \mathrm{~mL}$ acetone was used) for analysis. Soil and crop samples collected from the treated field were prepared with the method described above and analyzed using GC-ECD (Fig. 1).

\section{Dissipation and half-life in soil}

Dissipation of pesticide in soil was determined by firstorder kinetics regression analysis with the following model [30].

$C_{t}=C_{0} \mathrm{e}^{-k t}$

where $\mathrm{C}_{t}$ is the concentration of pesticide at any time $t, \mathrm{C}_{0}$ is the initial concentration, and $k$ is the rate of constant in days.The half-life $\left(\mathrm{DT}_{50}\right)$, which is the time taken for the concentration of the initial deposits to decline by $50 \%$, was determined by the following equation:

$$
\begin{aligned}
\mathrm{DT}_{50} & =\ln 2 \times k^{-1} \\
& =0.693 / k
\end{aligned}
$$

\section{Calculation of crop-bioconcentration ratio (CBR)}

Crop-to-soil bioconcentration ratio is used to relate the concentration of chemical measured in the crop to that in the soil supporting the crop. CBR was calculated by dividing the residue concentration of pesticide in the crop by the concentration in soil at 0 DAT as per the following equation [31].

$$
\mathrm{CBR}=\frac{\text { Concentration in crop }(\mathrm{mg} / \mathrm{kg})}{\text { Initial concentration in soil }(\mathrm{mg} / \mathrm{kg})}
$$

\section{Results and discussion}

\section{Validation of the analytical method}

To evaluate the analytical performance, the recovery, reproducibility, method limit of quantitation, and linearity of the calibration curve were characterized.
Table 1 Instrument parameters for chlorpyrifos analysis

\begin{tabular}{ll}
\hline Instrument & Shimadzu GC-2010 \\
\hline Detector & Electron capture detector $(\mathrm{ECD})$ \\
Column & $\mathrm{DB}-5(0.25 \mathrm{~mm} \times 30 \mathrm{~m}, 0.25 \mu \mathrm{m}$ film thickness $)$ \\
Oven temperature & $200{ }^{\circ} \mathrm{C}(2 \mathrm{~min})-20{ }^{\circ} \mathrm{C} / \mathrm{min}-280{ }^{\circ} \mathrm{C}(5 \mathrm{~min})$ \\
Detector temperature & $300^{\circ} \mathrm{C}$ \\
Injection port temperature & $250{ }^{\circ} \mathrm{C}$ \\
Gas flow rate & Carrier $\left(\mathrm{N}_{2}\right): 1.3 \mathrm{~mL} / \mathrm{min} ;$ make up gas $\left(\mathrm{N}_{2}\right): 60.0 \mathrm{~mL} / \mathrm{min}$ \\
Injection mode & Split $(20: 1)$ \\
Injection volume & $1.0 \mu \mathrm{L}$ \\
Retention time & $4.8 \mathrm{~min}$ \\
\hline
\end{tabular}






Fig. 1 A schematic diagram of chlorpyrifos residue analysis in soil and Korean cabbage

The calibration curve of chlorpyrifos showed good linearity from 0.1 to $10 \mathrm{mg} / \mathrm{L}$ with the regression equation of $y=428022 x+35932$ and a correlation coefficient $\left(R^{2}\right)$ of 0.9998 .

Based on the analysis of the standard solution, $0.1 \mathrm{ng}$ was determined as the instrumental limit of quantitation (ILOQ), which was satisfactory for the residue analysis of chlorpyrifos.

The method limit of quantitation (MLOQ) is a practical LOQ for the total analytical method using samples and is calculated using the LOQ, injection volume, final solution volume, and sample weight in the analytical procedures [32].

$$
\begin{aligned}
\operatorname{MLOQ}(\mathrm{mg} / \mathrm{kg})= & (\mathrm{LOQ} \times \text { final solution volume }) / \\
& (\text { injection volume } \times \text { sample weight }) \\
\operatorname{MLOQ}(\mathrm{mg} / \mathrm{kg})= & (0.1 \mathrm{ng} \times 4 \mathrm{~mL}) /(1.0 \mu \mathrm{L} \times 20 \mathrm{~g}) \\
= & 0.02 \mathrm{mg} / \mathrm{kg}(\text { soil }) \\
= & (0.1 \mathrm{ng} \times 2 \mathrm{~mL}) /(1.0 \mu \mathrm{L} \times 10 \mathrm{~g}) \\
= & 0.02 \mathrm{mg} / \mathrm{kg}(\text { Korean cabbage })
\end{aligned}
$$

The MLOQ of chlorpyrifos was $0.02 \mathrm{mg} / \mathrm{kg}$ for soil and Korean cabbage. This value is suitable for the criteria set forth by the Korea Food and Drug Administration below $0.05 \mathrm{mg} / \mathrm{kg}$ or half of the MRL [33].

The efficiency of the analytical procedure used for extraction and purification was validated by the recovery rate prior to the quantitation of pesticides in the target samples. The control samples were spiked with chlorpyrifos standard solution at two different levels and then analyzed by following an established analytical method. Recovery rates from two different soils were $100.7-113.7 \%$, while that from Korean cabbage ranged from 98.5 to $104.8 \%$ (Table 2) with a low CV, less than 3.6 and $2.8 \%$, respectively. The GC chromatograms of soil and Korean cabbage samples are shown in Fig. 2. The retention time of chlorpyrifos was $4.7 \mathrm{~min}$, and no interfering peaks were observed in the untreated sample chromatogram of soil and Korean cabbage. Thus, the residue analytical method used in this study was adequate to quantify chlorpyrifos residue in samples.

\section{Dissipation of chlorpyrifos in the treated soil}

Chlorpyrifos residue in the soil of the untreated plot was lower than the MLOQ (0.02). Residue level in the treated soil in Field 1 on the day of $0.12 \mathrm{~g}$ a.i. $/ \mathrm{m}^{2}$ application was $1.15 \pm 0.04 \mathrm{mg} / \mathrm{kg}$, and this decreased to $0.22 \pm 0.02 \mathrm{mg} /$ $\mathrm{kg}$ after 36 days from the final treatment. The initial concentration of chlorpyrifos at $0.24 \mathrm{~g}$ a.i. $/ \mathrm{m}^{2}$ was $3.58 \pm 0.11 \mathrm{mg} / \mathrm{kg}$, which decreased to $0.49 \pm 0.02 \mathrm{mg} /$ $\mathrm{kg}$ after the same period (Fig. 3). The regression equations of dissipation were $C=1.2357 \mathrm{e}^{-0.025 t}\left(R^{2}=0.7703\right)$ and $C=3.7510 \mathrm{e}^{-0.0820 t}\left(R^{2}=0.9152\right)$, with half-lives of 27.7 and 9.6 days, respectively.

In Field 2, residue levels following treatment with 0.36 and $0.72 \mathrm{~g}$ a.i. $/ \mathrm{m}^{2}$ decreased to $3.03 \pm 0.22 \mathrm{mg} / \mathrm{kg}$ on 43 DAT from $20.89 \pm 0.92 \mathrm{mg} / \mathrm{kg}$ with the regression equation of $C=19.5248 \mathrm{e}^{-0.0461 t}\left(R^{2}=0.9600\right)$. Similarly, $59.27 \pm 5.01 \mathrm{mg} / \mathrm{kg}$ on 0 DAT decreased to $5.24 \pm 1.08 \mathrm{mg} / \mathrm{kg}$ on 43 DAT with the equation $C=55.7796^{-0.0682 t}\left(R^{2}=0.9525\right)$. The half-lives were 15.0 and 10.2 days with application rates of 0.36 and $0.72 \mathrm{~g}$ a.i. $/ \mathrm{m}^{2}$, respectively.

The half-live of chlorpyrifos in tested soil was 9.6-27.7 days. Degradation of chlorpyrifos in the cucumber-growing field resulted in half-lives of 25.7-73.0 days [11]. The half-live of chlorpyrifos in soil was 0.4-2.1 days in the cabbage field and 175-1576 days in five different soils treated with chlorpyrifos at $1000 \mathrm{mg} / \mathrm{kg}$ [5]. Pesticide dissipation is affected by climatic condition, treated amount, soil conditions, and the cultivation method. High $\log K_{\text {ow }}$ and low water solubility of chlorpyrifos can result in its long retention in soil and a long half-life.

\section{Concentration of chlorpyrifos in Korean cabbage}

Chlorpyrifos residue in Korean cabbage grown in the soil of the untreated plot was lower than the MLOQ (0.02). Conversely, the residue level of Korean cabbage grown in 
Table 2 Recovery of

chlorpyrifos from tested soil and Korean cabbage

\begin{tabular}{llll}
\hline Sample & Fortification level $(\mathrm{mg} / \mathrm{kg})$ & Recovery \pm C.V. $(\%)$ & MLOQ $(\mathrm{mg} / \mathrm{kg})$ \\
\hline Soil 1 (Field 1) & 0.2 & $106.3 \pm 3.0$ & 0.02 \\
& 1.0 & $102.3 \pm 1.5$ & \\
Soil 2 (Field 2) & 0.2 & $109.1 \pm 3.6$ & \\
& 1.0 & $102.7 \pm 0.4$ & \\
Korean cabbage & 0.2 & $102.4 \pm 2.8$ & \\
& 1.0 & $99.6 \pm 1.4$ & \\
\hline
\end{tabular}

(A)



(C)

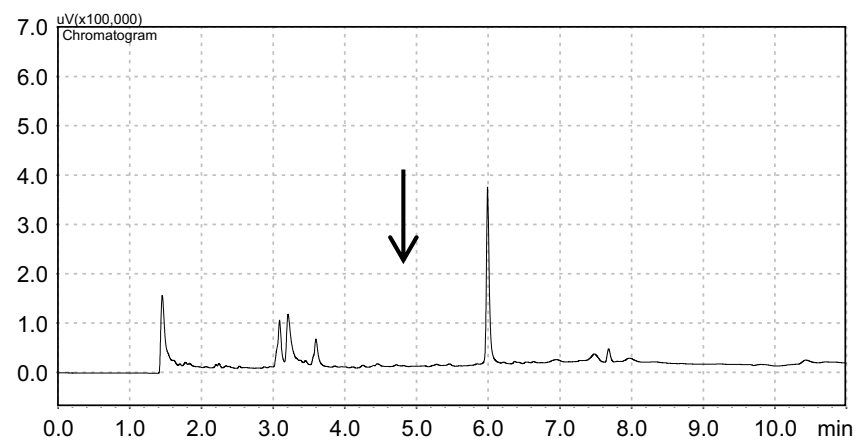

(B)



(D)



Fig. 2 GC chromatograms of chlorpyrifos. (A) soil control (Field 1), (B) soil sample at 43 DAT (Field 1), (C) Korean cabbage control (Field 1), (D) Korean cabbage sample at 37 DAT (Field 1)
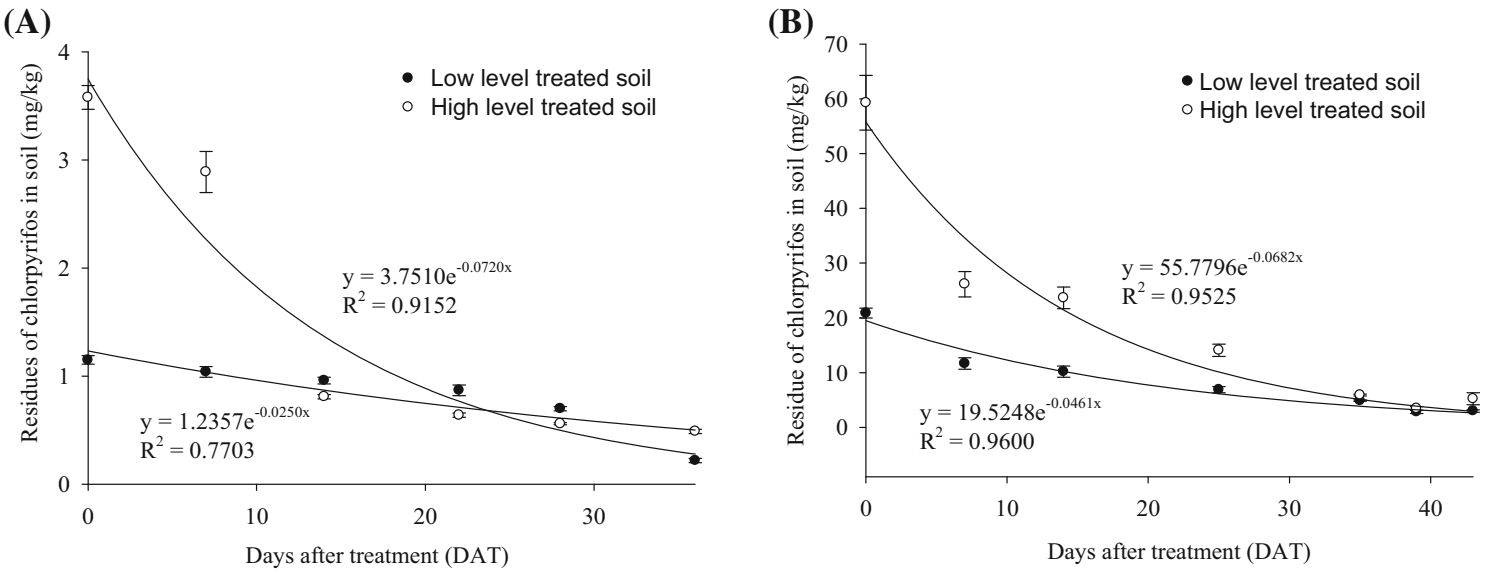

Fig. 3 Chlorpyrifos dissipation in the treated soils. (A) soil samples from Field 1, (B) soil samples from Field 2 
the field treated with $0.12 \mathrm{~g}$ a.i. $/ \mathrm{m}^{2}$ chlorpyrifos ranged from N.D (not detected) to $0.07 \pm 0.01 \mathrm{mg} / \mathrm{kg}$ in the 28 DAT sample. The residue level in Korean cabbage grown under $0.24 \mathrm{~g}$ a.i. $/ \mathrm{m}^{2}$ chlorpyrifos treatment ranged from $0.04 \pm 0.00 \mathrm{mg} / \mathrm{kg}$ at 36 DAT to $0.12 \pm 0.01 \mathrm{mg} / \mathrm{kg}$ at 28 DAT. In Field 2, treatment with the 0.36 and $0.72 \mathrm{~g}$ a.i. $/ \mathrm{m}^{2}$ rate resulted in residue levels of $0.38 \pm 0.08-0.54 \pm 0.09$ and $\quad 0.34 \pm 0.04-0.75 \pm 0.30 \mathrm{mg} / \mathrm{kg}, \quad$ respectively (Table 3). The residue decreased in proportion to time from treatment. The cabbage cultivated in Field 2 was larger than that cultivated in Field 1 at harvest and showed higher residual chlorpyrifos (Fig. 4). The residue level was proportional to the level of treated chemical. The average residue level in the plot treated with $0.72 \mathrm{~g}$ a.i. $/ \mathrm{m}^{2}$ was the highest at $0.55 \mathrm{mg} / \mathrm{kg}$, followed by $0.44 \mathrm{mg} / \mathrm{kg}$ at $0.36 \mathrm{~g}$ a.i. $/ \mathrm{m}^{2}$, and $0.08 \mathrm{mg} / \mathrm{kg}$ at $0.24 \mathrm{~g}$ a.i. $/ \mathrm{m}^{2}$.

\section{CBR of chlorpyrifos}

The CBR was calculated by comparing the concentration in the crop to the initial concentration in the soil. The initial concentrations of chlorpyrifos in soil were $1.15,3.58$, 20.89 , and $59.27 \mathrm{mg} / \mathrm{kg}$, respectively. The calculated CBRs are shown in Table 4. The highest average CBR was 0.06 at 28 DAT from Field 1. Therefore, $6.01 \%$ of the chlorpyrifos concentration compared with the initial soil concentration was observed in Korean cabbage. The Korean cabbages cultivated in Field 2 were larger than those cultivated in Field 1 at harvest (Fig. 4.). Therefore, the amount of residue in crop may be diluted through growth. Furthermore, the higher initial concentration in soil

Table 3 Levels of chlorpyrifos residue in Korean cabbage grown in treated soil

\begin{tabular}{lll}
\hline Sample (Field 1) & \multicolumn{2}{l}{ Residue $(\mathrm{mg} / \mathrm{kg})$} \\
\cline { 2 - 3 } & $0.12 \mathrm{~g}$ a.i. $/ \mathrm{m}^{2}$ treated & $0.24 \mathrm{~g}$ a.i. $/ \mathrm{m}^{2}$ treated \\
\hline $22 \mathrm{DAT}$ & N.D. & $0.03 \pm 0.01$ \\
$25 \mathrm{DAT}$ & N.D. & $0.08 \pm 0.01$ \\
28 DAT & $0.07 \pm 0.01$ & $0.12 \pm 0.01$ \\
32 DAT & N.D. & $0.11 \pm 0.02$ \\
36 DAT & N.D. & $0.04 \pm 0.00$ \\
\hline Sample (Field 2) & Residue $(\mathrm{mg} / \mathrm{kg})$ & \\
\cline { 2 - 3 } & $0.36 \mathrm{~g}$ a.i. $/ \mathrm{m}^{2}$ treated & $0.72 \mathrm{~g} \mathrm{a.i.} / \mathrm{m}^{2}$ treated \\
\hline 35 DAT & $0.45 \pm 0.03$ & $0.75 \pm 0.30$ \\
37 DAT & $0.54 \pm 0.09$ & $0.66 \pm 0.02$ \\
39 DAT & $0.39 \pm 0.07$ & $0.49 \pm 0.04$ \\
41 DAT & $0.45 \pm 0.13$ & $0.53 \pm 0.12$ \\
43 DAT & $0.38 \pm 0.08$ & $0.34 \pm 0.04$ \\
\hline
\end{tabular}

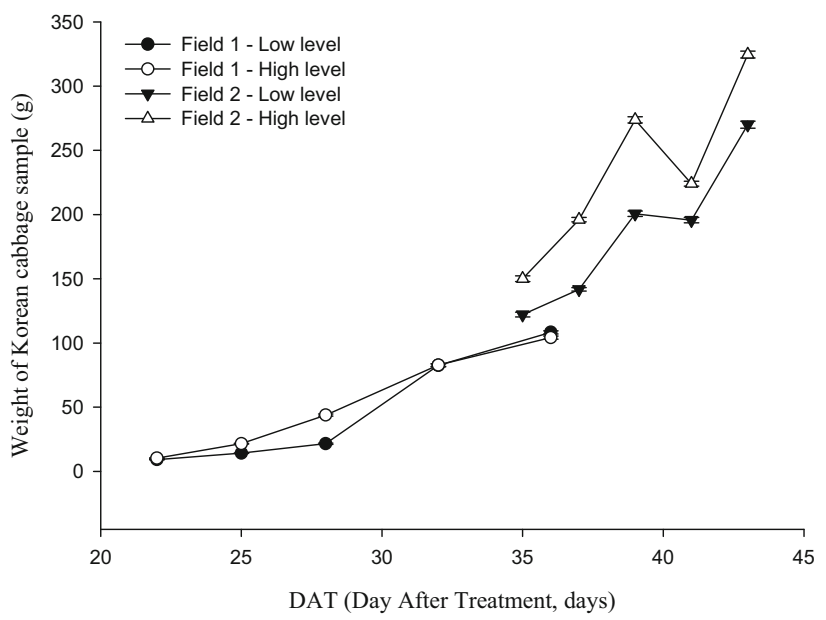

Fig. 4 Weight changes of Korean cabbage during cultivation

Table 4 Crop-bioconcentration ratio (CBR) of chlorpyrifos in Korean cabbage

\begin{tabular}{lll}
\hline Sample (Field 1) & CBR & \\
\cline { 2 - 3 } & $0.12 \mathrm{~g}$ a.i. $/ \mathrm{m}^{2}$ treated & $0.24 \mathrm{~g}$ a.i. $/ \mathrm{m}^{2}$ treated \\
\hline 22 DAT & N.D. & $0.010 \pm 0.003$ \\
25 DAT & N.D. & $0.023 \pm 0.002$ \\
28 DAT & $0.060 \pm 0.004$ & $0.034 \pm 0.004$ \\
32 DAT & N.D. & $0.029 \pm 0.005$ \\
36 DAT & N.D. & $0.011 \pm 0.001$ \\
\hline Sample (Field 2) & CBR & \\
\cline { 2 - 3 } & $0.36 \mathrm{~g}$ a.i. $/ \mathrm{m}^{2}$ treated & $0.72 \mathrm{~g} \mathrm{a.i.} / \mathrm{m}^{2}$ treated \\
\hline 35 DAT & $0.021 \pm 0.002$ & $0.013 \pm 0.001$ \\
37 DAT & $0.026 \pm 0.004$ & $0.011 \pm 0.001$ \\
39 DAT & $0.019 \pm 0.003$ & $0.008 \pm 0.001$ \\
41 DAT & $0.022 \pm 0.006$ & $0.009 \pm 0.002$ \\
43 DAT & $0.018 \pm 0.004$ & $0.006 \pm 0.001$ \\
\hline
\end{tabular}

resulted in a lower CBR value as calculated by the equation. The average CBR was inversely proportional to the treated amount of chemical for the same reason. The average CBR in the plot treated with $0.24 \mathrm{~g}$ a.i. $/ \mathrm{m}^{2}$ was the highest at 0.028 , followed by 0.021 with $0.36 \mathrm{~g}$ a.i. $/ \mathrm{m}^{2}$, and 0.001 with $0.72 \mathrm{~g}$ a.i. $/ \mathrm{m}^{2}$. Therefore, to harvest Korean cabbage containing chlorpyrifos less than the MRL $(0.2 \mathrm{mg} / \mathrm{kg})$, the maximum concentration of chlorpyrifos in the cultivation soils should be $3.3 \mathrm{mg} / \mathrm{kg}$ based on the highest CBR (0.06).

The residual pesticide in soil could be absorbed by Korean cabbage depending on the physiochemical properties of the target pesticide, especially the water solubility of the pesticide. Korean cabbage absorbed 2.2 and $2.4 \%$ of boscalid residue when grown in boscalid-treated soil. The 
rate of chlorfenapyr uptake by the cabbages was 1.3 and $1.5 \%$ of the soil concentrations of chlorfenapyr [25]. In this study, Korean cabbage absorbed $0.6-3.4 \%$ of the initial concentration of residue in soil. The rate of boscalid uptake by Korean cabbage was higher than that of chlorfenapyr. The water solubility of boscalid, chlorfenapyr, and chlorpyrifos was $4.6,0.14$, and $1.4 \mathrm{mg} / \mathrm{L}$; the $\log P$ value of these chemicals was $2.96,4.83$, and 4.7 respectively. Boscalid is more polar and water soluble and is therefore more rapidly absorbed and translocated to the upper part of Korean cabbage through the evaporation stream [25, 34]. In addition to water solubility, the systemic properties of pesticides are essential for understanding their uptake and translocation in the crop plant. Chlorpyrifos is a systemic insecticide absorbed from the root and translocated to the upper part. Conversely, chlorfenapyr is limited systemically, and boscalid is a foliar fungicide with translaminar and acropetal movement within the plant leaf; however, the systemic effect of boscalid is not well known [2].

The uptake of chlorpyrifos to Korean cabbage grown in chlorpyrifos-treated soil with 20 or $40 \mathrm{mg} / \mathrm{kg}$ increased up to 15 days and decreased thereafter, with uptake rates of $1.0-1.3 \%$ compared with the initial concentration in soils. Most residues that translocate to cucumber plant can be detected in the root, followed by the stem and leaf. The concentration reported in cucumber fruit is less than $0.02 \mathrm{mg} / \mathrm{kg}$ [11]. Cucumber plants, including the stem, leaf, and fruit, are larger than Korean cabbages; therefore, the concentration in cucumber plant is less than that in Korean cabbage due to the dilution effect resulting from fast growth [11]. The absorbed chlorpyrifos can be distribution to different plant parts in cucumber, whereas absorbed chlorpyrifos in Korean cabbage is translocated to the upper edible part only. This explains the higher concentration in Korean cabbage than in cucumber.

The contaminant in soil could be absorbed to soil particles and by plant roots following elution into soil water. This indicates the partition of pesticide between soil particles and water, and soil, water, and plants are important for the translocation of pesticide to plant. Estimation of pesticide concentrations in crops based on water-extractable residue can prevent the production of crops contaminated with pesticide residue from soils.

To understand plant uptake and to ensure the safety of crops grown in contaminated soil with pesticide, further studies investigating soil type, contaminant concentration in soils, types of crop, cultivating period, and distribution of absorbed pesticide in edible parts should be conducted.

Acknowledgments This work was financially supported by Cooperative Project "PJ010876012017" from the Rural Development Administration, Korea.

\section{References}

1. Sasikala C, Jiwal S, Rout P, Ramya M (2012) Biodegradation of chlorpyrifos by bacterial consortium isolated from agriculture soil. World J Microbiol Biotechnol 28:1301-1308

2. Tomlin CDS (2015) A world compendium the pesticide manual, 15th edn. British Crop Protection Council, Alton

3. Oliver GR, Bolles HG, Shurdut BA (2000) Chlorpyrifos: probabilistic assessment of exposure and risk. Neurotoxicology 21:203-208

4. Johnson DE, Seidler FJ, Slotkin TA (1998) Early biochemical detection of delayed neurotoxicity resulting from developmental exposure to chloropyrifos. Brain Res Bull 45:143-147

5. Randhawa MA, Anjum FM, Ahmed A, Randhawa MS (2007) Field incurred chlorpyrifos and 3,5,6-trichloro-2-pyridinol residues in fresh and processed vegetables. Food Chem 103:1016-1023

6. EPA (2000) Chlorpyrifos revised risk assessment and agreement with registrant. Environmental Protection Agency, Washington, DC

7. KCPA (2016) Using guideline of crop protection agents. Korea Crop Protection Association, Samjung Inc., Seoul

8. Paterson S, Mackay D (1994) A model of organic chemical uptake by plants form soil and the atmosphere. Environ Sci Technol 28:2259-2266

9. Park BJ, Lee BM, Kim CS, Park KH, Park SW, Kwon H, Kim JH, Choi GH, Lim SJ (2013) Long-term monitoring of pesticide residues in arable soils in Korea. Korean J Pestic Sci 17:283-292

10. Kim HK, Choi DS, Kim SG (2013) Analysis of recent four years situation for pesticide residues in the GAP certified agricultural products analyzed by national agricultural cooperative federation. Korean J Pestic Sci 17:271-282

11. Hwang JI, Jeon SO, Lee SH, Lee SE, Hur JH, Kim KR, Kim JE (2014) Distribution patterns of organophosphorous insecticide chlorpyrifos absorbed from soil into cucumber. Korean J Pestic Sci 18:148-155

12. Li H, Sheng G, Chiou CT, Xu O (2005) Relationship of organic contaminant equilibrium sorption and kinetic uptake in plants. Environ Sci Technol 39:4864-4870

13. Lichtenstein EP (1959) Plant absorption of insecticides, absorption of some chlorinated hydrocarbon insecticide form soil into various crops. J Agric Food Chem 7:430-434

14. Lichtenstein EP (1960) Insecticide uptake from soils, insecticidal residues in various crops grown in soils treated with abnormal rates of aldrin and heptachlor. J Agric Food Chem 8:448-451

15. Lichtenstein EP, Myrdal GR, Schulz KR (1965) Insecticide uptake from soils, absorption of insecticidal residues from contaminated soils into five carrot varieties. J Agric Food Chem 13:126-131

16. Lim DH, Lim DS, Keum YS (2016) Translocation of polychlorinated biphenyls in carrot-soil systems. Korean J Pestic Sci 20:203-210

17. Chiou CT, Sheng G, Manes M (2001) A partition-limited model for the plant uptake of organic contaminants form soil and water. Environ Sci Technol 35:1437-1444

18. Briggs GG, Bromilow RH, Evans AA (1982) Relationship between lipophilicity and root uptake and translocation of nonionized chemicals by barley. Pestic Sci 13:495-504

19. Trapp S (1995) Plant contamination: modeling and simulation of organic chemical processes. Lewis Publishers, Boca Raton

20. Briggs GG, Bromilow RH, Evans AA, Williams M (1983) Relationship between lipophilicity and the distribution of nonionized chemicals in barley shoots following uptake by the roots. Pestic Sci 14:492-500 
21. Hsu FC, Marxmiller RL, Yang AYS (1990) Study of root uptake and xylem translocation of cinmethylin and related compounds in detopped soybeans roots using a pressure chamber technique. Plant Physiol 93:1573-1578

22. Burken JG, Schnoor JL (1998) Predictive relationships for uptake or organic contaminants by hybrid poplar trees. Environ Sci Technol 32:3379-3385

23. Trapp S, McFarlane C, Matthies M (1994) Model for uptake of xenobiotics into plant: validation with bromacil experiment. Environ Toxicol Chem 13:413-422

24. Alkorta I, Garbisu C (2001) Phytoremediation of organic contaminants in soils. Bioresour Technol 79:273-276

25. Jeon SO, Hwang JI, Lee SH, Kim JE (2014) Uptake of boscalid and chlorfenapyr residues in soil into Korean cabbage. Korean $\mathbf{J}$ Pestic Sci 18:314-320

26. Lee EH, Hwang JI, Kim JE (2014) Patterns of uptake and removal by processing types of triazole fungicides in onion. Korean J Pestic Sci 19:248-254

27. Motoki Y, Iwafune T, Seike N, Otani T, Akiyama Y (2015) Relationship between plant uptake of pesticides and water-extractable residue in Japanese soils. J Pestic Sci 40:175-183

28. Collins C, Fryer M, Grosso A (2006) Plant uptake of nonionic organic chemicals. Environ Sci Technol 40:45-52
29. Dowdy DL, McKone TE (1997) Predicting the bioconcentration of organic chemicals from soil or air into plants using quantitative structure-activity relationships. Environ Toxicol Chem 16:2448-2456

30. Hwang KW, Bang WS, Jo HW, Moon JK (2015) Dissipation and removal of the etofenprox residue during processing in spring onion. J Agric Food Chem 63:6675-6680

31. McKone TE, Maddalena RL (2007) Plant uptake of organic pollutants from soil: bioconcentration estimates based on models and experiment. Environ Toxicol Chem 26:2494-2504

32. Lee JH, Park HW, Keum YS, Kwon CH, Lee YD, Kim JH (2008) Dissipation pattern of boscalid in cucumber under greenhouse condition. Korean J. Pestic Sci 12:67-73

33. Lee YD (2013) Practical guide for food code pesticide residue analysis (Extended ed), Osong, Korea

34. Juraske R, Vivas CSM, Velesquez AE, Santos GG, Moreno MBB, Gomez JD, Binder CR, Hellweg S, Dallos JAD (2011) Pesticide uptake in potatoes: model and field experiments. Environ Sci Technol 45:651-667 